\title{
Association between the transcriptional levels of Htr-1a and tryptophan hydroxylase- 1 in the hippocampus and the antifatigue effects of leucine on rats with postoperative fatigue
}

\author{
TIANTIAN WU ${ }^{1}$, JING CHEN ${ }^{2}$, JIANG ZHU ${ }^{1}$ and ZHEN YU ${ }^{3}$ \\ Departments of ${ }^{1}$ Gastrointestinal Surgery and ${ }^{2}$ Rheumatology, The First Affiliated Hospital, \\ Wenzhou Medical University, Wenzhou, Zhejiang 325035; ${ }^{3}$ Department of General Surgery, \\ Shanghai Tenth People's Hospital Affiliated to Tongji University, Shanghai 200072, P.R. China
}

Received February 13, 2014; Accepted July 16, 2014

DOI: 10.3892/etm.2014.1973

\begin{abstract}
Leucine (Leu), a branched-chain amino acid (BCAA), is widely used in clinical practice following severe burns, gastrointestinal surgery, trauma and sepsis. In the present study, the antifatigue effects of BCAAs on a postoperative fatigue (POF) rat model, induced by $70 \%$ intestinal resection, were investigated. Leu (16.5 g/l) was administered intraperitoneally at a dose of $18 \mathrm{ml} / \mathrm{kg} / \mathrm{day}$. The fatigue level and antifatigue effects of Leu were evaluated by open-field testing on day 1, 3, 5 and 7 after surgery. In addition, mRNA specimens were extracted and measured using a quantitative polymerase chain reaction method. The open-field test results indicated that Leu exhibited a significant antifatigue effect. The total distance travelled and the number of times the rats passed from the outermost grids of an open-top case were greatly improved in the Leu treatment group when compared with the POF model group. With the exception of the normal group, the mRNA expression levels of Htr-1a exhibited a similar trend in all other groups, reaching a climax on day 3 and 5, while being restored to a normal level on day 7 . With regard to the Leu intervention group, the mRNA expression level of Htr-1a decreased significantly on day 3 and 5 following surgery. The mRNA expression levels of tryptophan hydroxylase-1 were unchanged in this short time period; however, the levels were increased gradually in the Leu treatment group. Therefore, Leu exhibited an apparent antifatigue effect on various 5-hydroxytryptamine-associated genes.
\end{abstract}

Correspondence to: Dr Zhen Yu, Department of General Surgery, Shanghai Tenth People's Hospital Affiliated to Tongji University, 301 Yanchang Middle Road, Shanghai 200072, P.R. China E-mail: yuzhen0577@163.com

Key words: leucine, postoperative fatigue, open-field test, Htr-1a, tryptophan hydroxylase-1, quantitative polymerase chain reaction

\section{Introduction}

Currently, recovery in the postoperative period is receiving increasing attention. The concept of postoperative fatigue (POF) was first proposed by Professor Christensen (1), and is a common complication following surgery, particularly after enteral surgery. The fatigue manifests as central and peripheral symptoms. Depression, concentration difficulties, lethargy and weakness may be present for one to three months, even following uncomplicated abdominal surgery (2). POF increases treatment costs after surgery and burdens patients and their families. Etiological studies of POF have proposed that the condition is an endocrine-metabolic response to surgical and anesthetic stress. The behavioural and subjective changes during the postoperative convalescence are assumed to be the the physiological and metabolic consequences of surgery (3); therefore, developing a systemic therapy to abate POF and shorten the recovery period is desirable in surgery.

Leucine (Leu) is one of the three branched-chain amino acids (BCAAs; leucine, isoleucine and valine), which are essential amino acids. BCAAs, used as nutrient supplements, have an anticatabolic effect in the recovery period after exercise and decrease the muscle damage (4). BCAAs also contribute to the recovery from fatigue via the chemical reduction of tryptophan (Trp), allowing the molecule to pass through the blood-brain barrier and form the neurotransmitter, 5-hydroxytryptamine (5-HT) (5). Currently, BCAAs are used worldwide as nutrient supplements in bodybuilding and medicine, since further evidence has demonstrated that they accelerate the rate of myoprotein synthesis. Leu-only-supplemented nutrition was found to be promising, although further evaluation is required (6). However, the Trp-5-HT-central fatigue hypothesis, which is based on the principles of depression, anhypnia and dementia, has not been fully acknowledged (7).

5 -HT was found to be a relative frequent fatigue factor in 1987, with its synthesis and reactive receptors contributing to the feeling of fatigue (central fatigue) (8). Observations from studies on sports fatigue revealed that the presence of high concentrations of 5-HT in the hippocampi of rats led to fewer symptoms of depression, such as malaise, somnolent, lethargy and debilitation (9-11). This may be caused by factors 
associated with synthesis. In a previous study, the total concentration of 5-HT in the brains of different postoperative rats were identified to have a similar trend (12). Therefore, the aim of the present study was to identify the expression levels of the tryptophan hydroxylase-1 (TPH-1) gene, the crucial enzyme in the pathway of 5-HT synthesis in the brain, and the 5-HT receptor $1 \mathrm{~A}$ (Htr-1a) gene, the main receptor of 5-HT in the brain. In addition, the study analyzed the association between $\mathrm{POF}$ and these gene expression levels.

\section{Materials and methods}

Animals. In total, 128 adult specific-pathogen free male Sprague-Dawley rats (weight, $430 \pm 20 \mathrm{~g}$ ) were obtained from Beijing Vital River Laboratories (Beijing, China). Experimental procedures were approved by the Institutional Animal Committee of Wenzhou Medical University (Wenzhou, China). All the rats in the experiment were treated according to the 'Guide for the Care and Use of Laboratory Animals', and were maintained in specific-pathogen free conditions throughout the experiment. The temperature was controlled at $20-25^{\circ} \mathrm{C}$, the humidity was maintained at $45-55 \%$ and the lighting was $10 \mathrm{~h}$ light/14 h dark per cycle. The rats were fed normally, with the exception of the days prior to and following surgery when they were forbidden to eat.

Grouping and surgery. The rats were divided randomly into groups of 32 rats each: Normal group (NG; no interventions); sham operation group (SG; opened and closed abdomen); POF model group (MG; 70\% small intestinal resection) (11) and Leu-treated POF model group (LG; treated with Leu on the basis of the MG). Each group was subdivided into day 1, 3, 5 and 7 subgroups, which indicated the number of days after surgery (for the NG, there was no change among the subgroups as no surgery was carried out). All the rats were anesthetized by an abdominal injection of $10 \%$ chloral hydrate $(0.35 \mathrm{ml} / \mathrm{kg})$ prior to surgery. Rats in the LG group were administered Leu (Sigma-Aldrich,St. Louis, MO, USA) dissolved in saline solution $(16.5 \mathrm{~g} / \mathrm{l})$, at a dose of $18 \mathrm{ml} / \mathrm{kg} / \mathrm{day}$, by abdominal injection. All rats were fed normally prior to and following surgery (with the exception of the fasting days the days before and after surgery). The $70 \%$ small intestinal resection is illustrated in Fig. 1.

Open-field test. Each rat was placed in the center of one of the 25 equal squares of an open-top black case $(100 \times 100 \times 50 \mathrm{~cm})$. The motion curve, total distance travelled and the number of times the rat passed through the outermost grids and central square in 5 min were recorded using an image acquisition system (Sony HDR-CX220E; Sony Corporation, Tokyo, Japan). Counting these frequencies and the number of times that the rats cleaned their face, mouth and head with their forelimb was performed manually.

Quantitative polymerase chain reaction ( $q P C R)$. Hippocampus specimens were obtained after perfusion from the left ventricle using normal saline solution. Total RNA was extracted from the hippocampus tissues with TRIzol reagent (Invitrogen Life Technologies, Grand Island, NY, USA). The

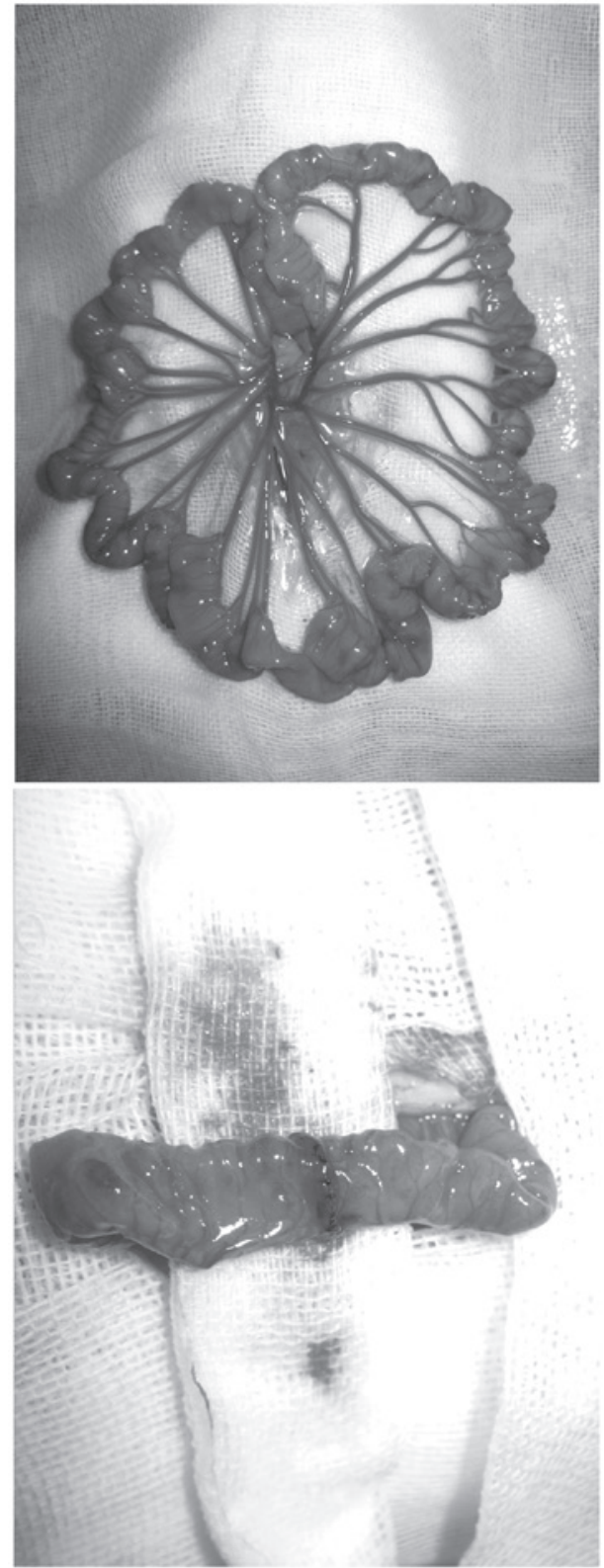

Figure 1. Mesenteric vessels were ligated, $70 \%$ of the intestine was cut and the remnant was anastomosed.

extracted RNA samples were precipitated in isopropanol and incubated at $-20^{\circ} \mathrm{C}$ overnight. Next, the samples were dissolved in diethylpyrocarbonate-treated water and stored at $-80^{\circ} \mathrm{C}$. An ultraviolet spectrophotometer (DU-800; Beckman Coulter ${ }^{\circledR}$, Miami, FL, USA) was used for quantification and qualification. The RNA samples used in this experiment had an A260/A280 ratio in the range of 1.8-2.0. The integrity of the RNA was identified using agarose gel electrophoresis (13). Next, $1 \mu \mathrm{l}$ RNA $(1,000 \mathrm{ng} / \mu \mathrm{l})$ was reverse transcribed to $20 \mu \mathrm{l}$ cDNA using a reverse transcription kit (Toyobo Corporation, Osaka, Japan). Glyceraldehyde-3-phosphate dehydrogenase (GAPDH), a housekeeping gene, was selected as the internal control. According to the manufacturer's instructions provided in the SYBR ${ }^{\circledR}$ Green kit (Toyobo Corporation), the qPCR reaction mixtures $(10 \mu \mathrm{l})$ of the genes, GAPDH, TPH-1 and Htr-1a, consisted of $1 \mu \mathrm{l}$ cDNA, $0.6 \mu \mathrm{l}$ sense primer $(10 \mu \mathrm{M}$; Invitrogen Life Technologies), $0.6 \mu \mathrm{l}$ antisense primer $(10 \mu \mathrm{M}$; 
Table I. Sequences of the Htr-1a and TPH-1 genes.

\begin{tabular}{lll}
\hline Gene name & Sense sequence (5'-3') & Antisense sequence $\left(5^{\prime}-3^{\prime}\right)$ \\
\hline Htr-1a & gtgccggctgcttcttcc & gcgctggttatgctcttgctgtct \\
TPH-1 & atggggcagtgaggcagggtgacg & ccaagcaggcgggggcataggagt \\
GAPDH & ggtgctgagtatgtcgtgga & gccatgccagtgagcttccc \\
\hline
\end{tabular}

TPH-1, tryptophan hydroxylase-1; GAPDH, glyceraldehyde-3-phosphate dehydrogenase.

Table II. Results of the open-field test.

\begin{tabular}{|c|c|c|c|c|c|c|}
\hline \multirow[b]{2}{*}{ Groups } & \multirow[b]{2}{*}{ Rats (n) } & \multicolumn{3}{|c|}{ Horizontal movement } & \multicolumn{2}{|c|}{ Vertical movement } \\
\hline & & $\begin{array}{l}\text { Total distance } \\
\text { travelled }(\mathrm{m})\end{array}$ & $\begin{array}{l}\text { Times passing from } \\
\text { the outermost grids (n) }\end{array}$ & $\begin{array}{l}\text { Times passing from } \\
\text { central square }(\mathrm{n})\end{array}$ & $\begin{array}{l}\text { Explorations } \\
\text { (n) }\end{array}$ & $\begin{array}{c}\text { Clean } \\
\text { ups }(n)\end{array}$ \\
\hline NG-D1 & 8 & $19.00 \pm 3.79$ & $104.4 \pm 42.2$ & $2.0 \pm 0.8$ & $12.6 \pm 7.4$ & $2.8 \pm 2.1$ \\
\hline NG-D3 & 8 & $17.24 \pm 4.76$ & $112.4 \pm 38.9$ & $2.1 \pm 1.1$ & $14.3 \pm 6.2$ & $2.6 \pm 1.2$ \\
\hline NG-D5 & 8 & $18.36 \pm 5.21$ & $96.59 \pm 26.0$ & $1.8 \pm 1.0$ & $16.8 \pm 4.7$ & $1.8 \pm 1.6$ \\
\hline NG-D7 & 8 & $21.6 \pm 3.86$ & $117.5 \pm 19.8$ & $2.0 \pm 1.2$ & $12.6 \pm 6.5$ & $2.6 \pm 1.4$ \\
\hline SG-D1 & 8 & $11.51 \pm 2.66^{\mathrm{a}}$ & $71.1 \pm 13.9^{\mathrm{a}}$ & $2.1 \pm 1.1$ & $6.4 \pm 3.9^{\mathrm{a}}$ & $1.9 \pm 1.7$ \\
\hline SG-D3 & 8 & $15.33 \pm 2.85^{\mathrm{a}}$ & $104.9 \pm 21.8^{\mathrm{a}}$ & $1.6 \pm 0.9$ & $12.4 \pm 5.0$ & $2.6 \pm 2.4$ \\
\hline SG-D5 & 8 & $19.12 \pm 2.40$ & $139.0 \pm 31.7$ & $2.0 \pm 1.1$ & $13.0 \pm 5.8$ & $3.6 \pm 2.8$ \\
\hline SG-D7 & 8 & $18.42 \pm 3.93$ & $121.5 \pm 24.8$ & $1.8 \pm 1.0$ & $17.3 \pm 6.2$ & $3.5 \pm 2.2$ \\
\hline MG-D1 & 8 & $10.52 \pm 4.98^{\mathrm{a}}$ & $60.0 \pm 18.9^{\mathrm{a}}$ & $1.1 \pm 0.4$ & $4.6 \pm 2.6^{\mathrm{a}}$ & $2.6 \pm 2.4$ \\
\hline MG-D3 & 8 & $9.75 \pm 2.59^{\mathrm{a}}$ & $69.3 \pm 19.0^{\mathrm{a}}$ & $0.5 \pm 0.5$ & $9.0 \pm 4.0$ & $2.1 \pm 1.7$ \\
\hline MG-D5 & 8 & $12.69 \pm 2.07^{\mathrm{a}}$ & $118.0 \pm 15.7$ & $1.0 \pm 0.0$ & $13.4 \pm 5.4$ & $3.3 \pm 1.7$ \\
\hline MG-D7 & 8 & $17.34 \pm 3.50$ & $139.3 \pm 23.9$ & $1.3 \pm 0.5$ & $15.9 \pm 6.9$ & $3.3 \pm 2.4$ \\
\hline LG-D1 & 8 & $9.06 \pm 2.06^{\mathrm{a}}$ & $61.4 \pm 16.1^{\mathrm{a}}$ & $0.9 \pm 0.4$ & $5.9 \pm 2.2^{\mathrm{a}}$ & $3.9 \pm 2.5$ \\
\hline LG-D3 & 8 & $11.11 \pm 3.06^{\mathrm{a}}$ & $77.9 \pm 24.5^{\mathrm{a}, \mathrm{b}}$ & $0.8 \pm 0.5$ & $9.9 \pm 3.3$ & $2.9 \pm 1.4$ \\
\hline LG-D5 & 8 & $19.82 \pm 2.42^{\mathrm{b}}$ & $136.4 \pm 19.1^{\mathrm{b}}$ & $0.9 \pm 0.6$ & $15.1 \pm 4.9$ & $5.1 \pm 3.4$ \\
\hline LG-D7 & 8 & $23.21 \pm 3.63^{\mathrm{b}}$ & $153.3 \pm 23.4^{\mathrm{b}}$ & $1.0 \pm 0.5$ & $19.6 \pm 6.9$ & $4.9 \pm 3.5$ \\
\hline
\end{tabular}

Results are expressed as mean \pm standard deviation. ${ }^{\mathrm{a}} \mathrm{P}<0.05$, vs. NG-D1; ${ }^{\mathrm{P}}<0.05$, vs. MG at the same parameter. NG, normal group; $\mathrm{SG}$, sham operation group; MG, POF model group; LG, Leu-treated POF model group; Dn, day n (where n=1,3,5 or 7); Leu, leucine.

Invitrogen Life Technologies), $5 \mu$ l SYBR ${ }^{\circledR}$ Green (Toyobo

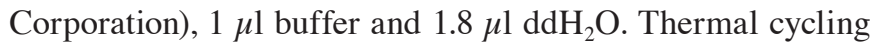
was performed in a $10-\mu 1$ volume with a 30 -sec preheating step at $95^{\circ} \mathrm{C}$, followed by 40 cycles of $5 \mathrm{sec}$ at $95^{\circ} \mathrm{C}, 10 \mathrm{sec}$ at $55^{\circ} \mathrm{C}$ and $15 \mathrm{sec}$ at $72^{\circ} \mathrm{C}$, following which a melting curve was constructed. The sense and antisense sequences of each gene are shown in Table I.

Statistical analysis. Statistical analysis was performed using SPSS 20.0 software (IBM, Armonk, NY, USA) for Windows. Open-field test results are expressed as the mean \pm standard deviation, and statistical significance was determined by one-way analysis of variance and the least significant difference t-test. The results from the qPCR are expressed as $2^{-\Delta \Delta \mathrm{Ct}}$, and were analyzed with the Student's t-test. $\mathrm{P}<0.05$ was considered to indicate a statistically significant difference.

\section{Results}

Results of open-field testing. The behavior of the rats in the MG was apathetic compared with the rats in the NG, showing decreased activity, hair loss and poor hygiene due to the lack of cleaning themselves. However, rats in the SG were more active compared with the MG rats on day 3,5 and 7 of the postoperative period. The injection of Leu improved the behavior of the rats in the $\mathrm{LG}$ when compared with the MG rats. The results of the open-field test are shown in Table II.

The total distance travelled and the number of times passing from the outermost grids for the SG rats were significantly lower compared with the NG rats on day 1 and 3 after surgery. However, the exploration periods of the SG rats were only significantly lower than that of the NG rats at day 1 after surgery. MG rats exhibited a significant reduction in the total distance travelled when compared with the NG rats on 
Table III. Results of qPCR.

\begin{tabular}{|c|c|c|c|}
\hline Groups & Rats (n) & Htr-1a & ТPH-1 \\
\hline MG-D1 & 8 & $1.0364 \pm 0.3998^{a}$ & $1.4710 \pm 0.6517$ \\
\hline MG-D3 & 8 & $40.1413 \pm 14.5137^{b}$ & $0.8461 \pm 0.6696$ \\
\hline MG-D5 & 8 & $21.8495 \pm 7.8794^{\mathrm{b}}$ & $1.4303 \pm 0.9012$ \\
\hline MG-D7 & 8 & $1.5624 \pm 1.5698^{a}$ & $3.1004 \pm 1.4620$ \\
\hline SG-D1 & 8 & $1.5274 \pm 1.3713^{\mathrm{a}}$ & $2.9534 \pm 1.2771$ \\
\hline SG-D3 & 8 & $47.2402 \pm 19.7972^{\mathrm{b}}$ & $0.6509 \pm 0.2823$ \\
\hline SG-D5 & 8 & $25.6668 \pm 8.6453^{b}$ & $1.3636 \pm 0.5345$ \\
\hline SG-D7 & 8 & $1.2369 \pm 0.9885^{\mathrm{a}}$ & $0.8305 \pm 0.4100$ \\
\hline LG-D1 & 8 & $1.4380 \pm 1.1323^{\mathrm{a}}$ & $1.2571 \pm 0.9843$ \\
\hline LG-D3 & 8 & $25.3650 \pm 6.3114^{c}$ & $5.6938 \pm 1.0210$ \\
\hline LG-D5 & 8 & $11.2531 \pm 3.7433^{c}$ & $10.2159 \pm 1.2561$ \\
\hline LG-D7 & 8 & $1.2406 \pm 1.2125^{\mathrm{a}}$ & $11.1382 \pm 1.3120$ \\
\hline \multicolumn{4}{|c|}{$\begin{array}{l}\text { Relative expression levels were calculated using the } 2^{-\Delta \Delta \mathrm{Ct}} \text { method } \\
\text { and are expressed as the mean } \pm \text { standard deviation. }{ }^{\mathrm{P}} \mathrm{P}>0.05 \text {, between } \\
\text { day } 1 \text { and } 7 \text { after surgery; }{ }^{\mathrm{P}} \mathrm{P}>0.05 \text {, between day } 3 \text { and } 5 \text { after surgery; } \\
\text { c } \mathrm{P}<0.05 \text {, vs. MG values. For the TPH- } 1 \text { gene, the values of LG-D5 } \\
\text { and LG-D7 were higher compared with the other subgroups }(\mathrm{P}<0.05 \text { ); } \\
\text { however, there was no significant difference between the values at D5 } \\
\text { and D7 (P }>0.05 \text { ). SG, sham operation group; MG, POF model group; } \\
\text { LG, Leu-treated POF model group; Dn, day n (where } \mathrm{n}=1,3,5 \text { or } 7 \text {; } \\
\text { qPCR, quantitative polymerase chain reaction; TPH-1, tryptophan } \\
\text { hydroxylase-1; Leu, leucine. }\end{array}$} \\
\hline
\end{tabular}

day 1, 3 and 5. In addition, the number of times the MG rats passed through the outermost grids was significantly lower compared with the NG rats on day 1 and 3 . The exploration periods of the MG rats showed no differences, with the exception of day 1 after surgery. The total distance travelled and the number of times the outermost grids were passed by the $\mathrm{LG}$ and MG rats on days 1 and 3 were similar. Certain indices returned to their normal levels in the LG rats at day 5 after surgery. The total distance travelled and the number of times the outermost grids were passed by the LG rats improved significantly on day 5 and 7 , when compared with the MG rats.

Results of $q P C R$. Relative quantification was employed to perform qPCR, and the results are expressed in terms of $2^{-\Delta \Delta \mathrm{Ct}}$ (Table III). Data for the Htr-1a gene indicated that the transcriptional levels of all the groups on day 1 and 7 after surgery were not significantly different from the NG. With the exception of the NG group, all groups followed a similar trend, showing an increase on day 3 , and a decrease on day 5. Statistically significant differences were not observed between the SG and MG on these two days; however, the LG exhibited statistically significant decreases when compared with these groups at these time points. With regard to the TPH-1 gene, the transcriptional levels in the SG and MG were similar for the whole postoperative period. By contrast, the transcriptional level in the LG increased significantly on day 5 and 7 after surgery; however, the difference between these two days was not significant.

\section{Discussion}

POF is a common postoperative symptom, appearing particularly after uncomplicated abdominal or thoracic surgery. Research on POF has helped shorten the recovery period and improve the quality of life following surgery. In a previous study, a fatigue model induced by $70 \%$ small intestinal resection was proposed (14). The present study demonstrated that the intervention of Leu upon this model induced an antifatigue effect. In addition, open-field testing revealed that Leu enhanced the activity of rats after surgery.

Previous studies have identified that the peripheral effects of 5-HT on neural networks inhibit sensory-generating and sensory-integrating processes, facilitate motor output and suppress the somatosensory system (15-18). However, the influence of 5-HT in the brain is more complicated. 5-HT deficiency has been hypothesized to be a cause of depression, which is supported by pharmacological studies in conjunction with etiological findings (19-21). By contrast, the levels of 5-HT in the anterior hypothalamic and hippocampal areas are increased in rats with fatigue caused by excessive exercise, surgery or diseases, such as cholestasis and neoplasm (22-24). When the concentration of 5-HT in the aforementioned tissues is decreased using pharmacological methods, the physical state is improved (11).

The present study investigated whether the transcriptional level of 5-HT-related genes changes in the short period following surgery in rats. Regardless of the administration of Leu, the mRNA expression levels of Htr-la changed in the postoperative period, increasing significantly on day 3 and 5 after surgery, and returning to normal levels on day 7 . When Leu was administered, the expression levels decreased significantly on day 3 and 5, as compared with the MG. However, the mRNA expression levels of TPH-1 were not altered unless Leu was injected into the abdominal cavity. The Htr-1a gene encodes mRNA that transcribes a G-protein coupled receptor on the pre- and postsynaptic membrane, which regulates the biosynthesis of downstream inhibitory substances (25). The TPH-1 gene encodes mRNA that transcribes an enzyme that catalyzes 5-HT synthesis and is the most predominant synthetase of 5-HT. Changes in the mRNA expression of Htr-1a were negatively correlated with the results of the open-field test. These gene activities indicate that fatigue after enteral surgery depends on changes in the expression of Htr-1a within a short postoperative period. However, when Leu was administered daily for a relatively long period, the gene expression of TPH-1 changed accordingly on day 5 and 7. Therefore, surgery may not alter the transcriptional level of the TPH-1 gene.

5-HT receptors modulate the release of numerous neurotransmitters (with the exception of serotonin), including glutamate, GABA, dopamine and epinephrine, as well as a number of hormones, including oxytocin, prolactin, vasopressin and cortisol (26). 5-HT 1A receptors are the most common 5-HT receptors. In areas such as the hippocampus, amygdala and septum, 5-HT 1A receptors function as postsynaptic receptors (27). The present study demonstrated that therapy with Leu may decrease the density of 5-HT 1A receptors on postsynaptic membranes; thus, abate the inhibitory affect of 5-HT in neuromodulation. Additionally, Leu therapy 
may increase TPH-1 density in neurons, and thus, control the synthesis of 5-HT.

In conclusion, Leu has been found to have an antifatigue effect on a rat model of POF induced by $70 \%$ intestinal resection. Although numerous pharmacological mechanisms exist, the present study investigated the transcription of two genes in the seven-day period after surgery. However, further research is required since neurotransmitters, other associated genes and the expression of these genes remain unknown.

\section{Acknowledgements}

The study was supported by grants from the National Natural Science Foundation of China (no. 81171857), the Natural Science Foundation of Zhejiang Province (no. LZ12H07001), the cofounded program between the Ministry of Health and Zhejiang Province (no. 201231118) and the clinical nutriology area of the medical support discipline of Zhejiang Province (no. 11-ZC24).

\section{References}

1. Christensen $\mathrm{T}$ and Kehlet $\mathrm{H}$ : Postoperative fatigue. World J Surg 17: 220-225, 1993.

2. Rubin GJ, Hardy R and Hotopf M: A systematic review and meta-analysis of the incidence and severity of postoperative fatigue. J Psychosom Res 57: 317-326, 2004.

3. Salmon P and Hall GM: A theory of postoperative fatigue: an interaction of biological, psychological, and social processes. Pharmacol Biochem Behav 56: 623-628, 1997.

4. Gastmann U and Lehmann MJ: Overtraining and the BCAA hypothesis. Med Sci Sports Exerc 30: 1173-1178, 1998.

5. Newsholme EA and Blomstrand E: Branched-chain amino acids and central fatigue. J Nutr 136 (1 Suppl): 274S-276S, 2006.

6. De Bandt JP and Cynober L: Therapeutic use of branched-chain amino acids in burn, trauma, and sepsis. J Nutr 136 (1 Suppl): 308S-313S, 2006.

7. Åstrand PO, Rodahi K, Dahl H and Strømme SB: Textbook of Work Physiology: Physiological Bases of Exercise. 4th edition. Human Kinetics, Champaign, IL, USA, 2003.

8. Newsholme EA, Acworth IN and Blomstrand E: Amino acids, brain neurotransmitters and a functional link between muscle and brain that is important in sustained exercise. In: Advances in Myochemistry. Benzi G (ed). John Libby Eurotext, London, pp127-138, 1987.

9. López-MuñozFand AlamoC:Monoaminergicneurotransmission: the history of the discovery of antidepressants from 1950s until today. Curr Pharm Des 15: 1563-1586, 2009.

10. Jacobsen JP, Medvedev IO and Caron MG: The 5-HT deficiency theory of depression: perspectives from a naturalistic 5-HT deficiency model, the tryptophan hydroxylase $2 \mathrm{Arg} 439$ His knockin mouse. Philos Trans R Soc Lond B Biol Sci 367: 2444-2459, 2012.
11. Tan S, Zhou F, Li N, et al: Anti-fatigue effect of ginsenoside $\mathrm{Rb} 1$ on postoperative fatigue syndrome induced by major small intestinal resection in rat. Biol Pharm Bull 36: 1634-1639, 2013.

12. Dong QT, Zhou F, Yu Z, Tan SJ, Wang Q and Zhang XD: Association of the changes of central serotonin and peripheral blood free amino acids with postoperative fatigue after abdominal surgery. Zhonghua Wei Chang Wai Ke Za Zhi 14: 968-972, 2011 (In Chinese).

13. Feng HZ, Wei B and Jin JP: Deletion of a genomic segment containing the cardiac troponin I gene knocks down expression of the slow troponin $\mathrm{T}$ gene and impairs fatigue tolerance of diaphragm muscle. J Biol Chem 284: 31798-31806, 2009.

14. Zhang XD, Chen BC, Dong QT, et al: Establishment and assessments of a new model for the postoperative fatigue syndrome by major small intestinal resection in rats. Scand $\mathrm{J}$ Gastroenterol 46: 1302-1309, 2011.

15. Barbeau $\mathrm{H}$ and Rossignol S: The effects of serotonergic drugs on the locomotor pattern and on cutaneous reflexes of the adult chronic spinal cat. Brain Res 514: 55-67, 1990.

16. Christenson J, Franck J and Grillner S: Increase in endogenous 5-hydroxytryptamine levels modulates the central network underlying locomotion in the lamprey spinal cord. Neurosci Lett 100: 188-192, 1989.

17. Harris-Warrick RM and Cohen AH: Serotonin modulates the central pattern generator for locomotion in the isolated lamprey spinal cord. J Exp Biol 116: 27-46, 1985.

18. Bizzi E, Giszter SF, Loeb E, Mussa-Ivaldi FA and Saltiel P: Modular organization of motor behavior in the frog's spinal cord. Trends Neurosci 18: 442-446, 1995.

19. Lapin IP and Oxenkrug GF: Intensification of the central serotoninergic processes as a possible determinant of the thymoleptic effect. Lancet 1: 132-136, 1969.

20. Coppen A: The biochemistry of affective disorders. Br J Psychiatry 113: 1237-1264, 1967.

21. Mendels J, Stinnett JL, Burns D and Frazer A: Amine precursors and depression. Arch Gen Psychiatry 32: 22-30, 1975.

22. Burak KW, Le T and Swain MG: Increased midbrain 5-HT1A receptor number and responsiveness in cholestatic rats. Brain Res 892: 376-379, 2001.

23. Terzioğlu B, Aypak C, Yananlı HR, et al: 5-hydroxytryptamine release in the anterior hypothalamic and the hippocampal areas of cholestatic rats. Life Sci 78: 1078-1083, 2006.

24. Uusitalo AL, Valkonen-Korhonen M, Helenius P, et al: Abnormal serotonin reuptake in an overtrained, insomnic and depressed team athlete. Int J Sports Med 25: 150-153, 2004

25. Sullivan GM, Ogden RT, Huang YY, et al: Higher in vivo serotonin-1A binding in posttraumatic stress disorder: a PET study with [11C]WAY-100635. Depress Anxiety 30: 197-206, 2013.

26. Ito H, Halldin C and Farde L: Localization of 5-HT1A receptors in the living human brain using [carbonyl-11C]WAY-100635: PET with anatomic standardization technique. J Nucl Med 40: 102-109, 1999.

27. Peroutka SJ: 5-Hydroxytryptamine receptor subtypes. Annu Rev Neurosci 11: 45-60, 1988. 